\title{
Evaluation of Prevalence of Signs and Symptoms of Temporomandibular Disorder in Dental Students of Navi Mumbai using the Helkimo Index
}

\author{
Pratik Chandrakant Malusare ${ }^{1}$, Bhakti Patil Soman², Nalini Tomar³ ${ }^{3}$ Snehal Patil ${ }^{4}$, Angela Kurian ${ }^{5}$
}

15enior Lecturer, Department of Oral Medicine and Radiology, G. D. Pol Foundation Y. M. T. Dental College, Navi

Mumbai, Maharashtra, India. ${ }^{2}$ Reader, Department of Oral Medicine and Radiology, G. D. Pol Foundation Y. M. T. Dental College, Navi Mumbai, Maharashtra, India. ${ }^{3}$ Senior Lecturer, Department of Oral Medicine and Radiology, G. D.

Pol Foundation Y. M. T. Dental College, Navi Mumbai, Maharashtra, India. ${ }^{4}$ Undergraduate Student, G. D. Pol Foundation Y. M. T. Dental College, Navi Mumbai, Maharashtra, India. ${ }^{5}$ Undergraduate Student, G. D. Pol Foundation Y. M. T. Dental College, Navi Mumbai, Maharashtra, India.

\section{ABSTRACT}

\section{BACKGROUND}

Temporomandibular joint disorder (TMD) is a broad term embracing a number of clinical manifestations which involves the temporomandibular joint (TMJ), masticatory muscles and the teeth. The most common symptoms are facial pain, headache, joint noises and limited mouth opening. Additionally, many signs may be present in these patients, such as tenderness, limited range of movement and deviation of mouth. However, the variation in symptoms among different population and in same patient at different times makes the diagnosis of this clinical entity difficult. The aim of this study was to evaluate the prevalence of TMD using Helkimo index in dental students of Navi Mumbai.

\section{METHODS}

A total of 426 dental students participated in the study (331 females; 95 males), with ages ranging between 19 and 26 years. Helkimo anamnestic index (Ai) and clinical dysfunction index (Di) were used to determine signs and symptoms respectively.

\section{RESULTS}

Fifty-nine females were affected among symptomatic patients who account for $18 \%$ of the female population, whereas only $10(11 \%)$ males were having symptoms. Out of the signs and symptoms present, sound in the TMJ was most common problem (45 students) which accounts for $10 \%$ followed by pain in 15 students (3\%) and fatigue in 7 students (2\%) in TMJ. On clinical examination, limited mouth opening was found in 40 students which accounts for $9 \%$ followed by locked mandible $(10$ students) $2 \%$, deviation (15 students) $3 \%$, and jaw rigidity of mandible (8 students) $2 \%$ during mouth opening.

\section{CONCLUSIONS}

The overall prevalence of TMJ dysfunction according to Helkimo index in this study was $16 \%$. TMD and its associated symptoms are common among students of health and science studies. The Helkimo index is a simple, inexpensive, effective and reliable screening index in identifying and classifying temporomandibular joint and TMD symptoms in patients according to the severity of the disorder in a specified population.

\section{KEY WORDS}

Helkimo Index, Temporomandibular Disorder, Temporomandibular Joint
Corresponding Author: Dr. Pratik Malusare, Senior Lecturer, Department of Oral Medicine \% Radiology, G. D. Foundation Y. M. T. Dental College, Kharghar, Navi Mumbai, Maharashtra, India.

E-mail: pratsmalu@gmail.com

DOI: $10.14260 /$ jemds/2019/692

Financial or Other Competing Interests: None.

\section{How to Cite This Article:}

Malusare PC, Soman BP, Tomar N, et al. Evaluation of prevalence of signs and symptoms of temporomandibular disorder in dental students of Navi Mumbai using the Helkimo index. J. Evolution Med. Dent. Sci. 2019;8(43):3190-3194, DOI: $10.14260 /$ jemds/2019/692

Submission 23-07-2019,

Peer Review 04-02-2019,

Acceptance 11-10-2019,

Published 28-10-2019. 


\section{BACKGROUND}

Temporomandibular joint disorder (TMD) is a broad term embracing a number of clinical manifestations which involve the temporomandibular joint (TMJ), masticatory muscles and the teeth.[1] The most common symptoms are facial pain, headache, joint noises and limited mouth opening. Additionally, many signs may be present in these patients, such as tenderness, limited range of movement and deviation of mouth.[2] However, the variation in symptoms among different population and in same patient at different times makes the diagnosis of this clinical entity difficult. Aetiology of TMD has been a debating topic for discussion. Earlier it was suggested that occlusal discrepancies are the major cause for TMD patients, but later on, in the 1960s and 1970s, emotional stress and occlusal discrepancy were considered as aetiology. Further with an increase in research work in TMD patients, it was found that the aetiology may include psychosocial, psychological, and physical factors. ${ }^{[3]}$ Temporomandibular dysfunction might influence any individual with different signs and symptoms irrespective of gender[4] or age, including children.[5] Some researchers claimed that university students (18-25 years old) had higher prevalence of TMD symptoms than older subjects.[6] and populations of rural areas.[7] As there are no criteria to attain a numeric value to decide the severity of TMD, indices play an important role to determine the prevalence of this disorder in a specified population. ${ }^{[3]}$ The application of indices is an excellent tool to assess disease severity and to standardize in order to examine the incidence of such problem in a specific population. The indices can be used to measure the effectiveness of the therapies employed and study etiologic factors. ${ }^{[8]}$

Helkimo was a pioneer in developing indexes to measure the severity of TMJ disorders, as well as pain in this system. He tried to assess the prevalence and severity of TMD in individuals and in general population through his index. This index was further broken down into anamnesis, clinical and occlusal dysfunction. [9] With increasing oral health awareness population, seeking treatment for TMD has increased. It is thus of paramount importance to have a standardized epidemiological data to estimate proportion and distribution of TMD in population even in asymptomatic patient population as initial signs and symptoms are variable which may worsen with time. The present study aims at cross-sectional epidemiological study for TMD signs and symptoms among dental students of Navi Mumbai through clinical examination and self-reported questionnaire.

\section{METHODS}

This descriptive cross-sectional study was conducted at a dental college of Navi Mumbai. A sample size estimation total number of 426 dental students with the age group of 19-26 years were randomly selected. This study was carried out between December 2018 and February 2019. Ethical approval was obtained from the Institutional Ethics Committee, and the subjects were required to sign an informed consent before their participation in the study.

\section{Sample Size Estimation}

Sample Size $=\left(\mathrm{Z}^{2} \mathrm{X}[\mathrm{p}] \mathrm{X}[\mathrm{I}-\mathrm{p}]\right) / \mathrm{C}^{2}$
Where $\mathrm{Z}=\mathrm{Z}$ value for the confidence level chosen
$\mathrm{p}=$ Percentage having a particular disease/ problem etc.
and it is expressed as a percentage
$\mathrm{C}=$ Confidence Interval $(\mathrm{CI})$ expressed, expressed as a
decimal.

The minimal sample size for the study was 372 according to the formula to obtain CI level of 0.95 , at least $80 \%$ power for analysis and alpha value of 0.05 . Thus, a sample size of 426 was determined considering the $15 \%$ attrition rate for the present study. The Helkimo Dysfunction Index was used to assess the prevalence of TMJ dysfunction.[10]

\section{Questionnaire}

The questionnaire designed by Helkimo was used to evaluate the degree of TMD in the participants. The necessary information was gathered from subjects who filled the questionnaire for any positive history of TMJ dysfunction. For the sign and symptoms of TMJ dysfunction, a clinical examination was performed as described by Helkimo.[10]

\section{Symptoms of TMJ Dysfunction}

Registration of subjective symptoms was accomplished with the help of a questionnaire. The questionnaire gathered demographic information along with answers to eight questions associated to subjective symptoms of $\mathrm{TM}$ J dysfunction.

Questionnaire was received, and it was analysed according to Anamnestic Scale [10] as follows-

Anamnestic Dysfunction Index Ai (Helkimo 1974)

- Ai0: denotes complete absence of subjective symptoms of dysfunction of the masticatory system. (i.e symptoms mentioned under AiI and AiII)

- Ail: denotes mild symptoms such as TMJ sounds (clicking and crepitation), feeling of stiffness or fatigue of the jaws.

- AilI: denotes severe symptoms of dysfunction. One or more of the following symptoms were reported in the anamnesis: difficulty in opening the mouth wide, locking, luxations, pain on movement, facial and jaw pain.

\section{Signs of TMJ Dysfunction}

1. Impaired Range of Movement- Maximal opening less than $40 \mathrm{~mm}$ and $35 \mathrm{~mm}$ for boys and girls respectively.

2. Impaired TMJ Function- Deviation of mandible was recorded if the mandibular midline deviated at least $2 \mathrm{~mm}$ during opening or closing. Stethoscope was used to record joint sounds of right and left sides after listening to each joint at least two times. During mandibular movements, locking and luxation were recorded.

3. Muscle Tenderness- Muscle tenderness was recorded by palpation of the temporalis, masseter, medial and lateral pterygoid muscles.

4. TMJ Tenderness- The joints were palpated from the lateral sides and via auditory meatus for tenderness. If found positive, there were recorded as palpable.

5. Pain on Movement of the Mandible- This was recorded when pain was present on wide mouth opening and during right and left lateral movements of the lower jaw. 
Clinical Dysfunction Index, Di, Based on Evaluation of Five Common Clinical Symptoms [Helkimo 1974][10]

\begin{tabular}{|c|c|c|}
\hline \multirow{3}{*}{ Criteria } & Normal range of movement & 0 \\
\cline { 2 - 3 } & Slightly impaired mobility & 1 \\
\cline { 2 - 3 } & Severely impaired mobility & 2 \\
\hline \multicolumn{2}{|c|}{ A. Symptom: Impaired Range of Movement/Mobility Index } \\
\hline
\end{tabular}

\begin{tabular}{|c|c|c|}
\hline \multirow{3}{*}{ Criteria } & $\begin{array}{c}\text { Smooth movement without TMJ joint sounds and } \\
\text { deviation on opening or closing movements } \leq 2 \mathrm{~mm}\end{array}$ & 0 \\
\cline { 2 - 3 } & $\begin{array}{c}\text { TMJ joint sounds in one or both joints and/or deviation } \\
\text { >2 mm on opening or closing movements. }\end{array}$ & 1 \\
\cline { 2 - 3 } & Locking and/or luxation of the TMJ joint. & 5 \\
\hline B. Symptom: Impaired TMJ Joint Function \\
\hline
\end{tabular}

\begin{tabular}{|c|c|c|}
\hline \multirow{3}{*}{ Criteria } & No tenderness to palpation in the masticatory muscles. & 0 \\
\cline { 2 - 3 } & Tenderness to palpation in 1-3 palpation sites & 1 \\
\cline { 2 - 3 } & Tenderness to palpation in 4 or more palpation sites & 5 \\
\hline \multicolumn{2}{|c|}{ C. Symptom Muscle Pain } \\
\hline
\end{tabular}

\begin{tabular}{|c|c|c|}
\hline \multirow{3}{*}{ Criteria } & No tenderness to palpation & 0 \\
\cline { 2 - 3 } & Tenderness to palpation laterally & 1 \\
\cline { 2 - 3 } & Tenderness to palpation posteriorly & 5 \\
\hline \multicolumn{2}{|c|}{ D. TMJ Joint Pain } \\
\hline
\end{tabular}

\begin{tabular}{|c|c|c|}
\hline \multirow{3}{*}{ Criteria } & No pain on movement & $\mathbf{0}$ \\
\cline { 2 - 3 } & Pain on one movement & 1 \\
\cline { 2 - 3 } & Pain on two or more movement. & $\mathbf{5}$ \\
\hline \multicolumn{2}{|c|}{ E. Symptom: Pain on Movement of Mandible } \\
\hline
\end{tabular}

Scores were assigned for the five symptoms and were summed up. Each individual had a total dysfunction score ranged from 0 to 25 points. The severity of disorder depends upon the score. Depending on the scores obtained, the patients were classified as follows: Di0- no dysfunction; DiI mild dysfunction (1-4 points); DiII- moderate dysfunction (59 points); DiIII- severe dysfunction (9-25 points).

\section{Statistical Analysis}

Data was compiled and entered into Microsoft excel sheet and the signs and symptoms of TMJ were presented as number and percentage of dental students.

\section{RESULTS}

A total of 426 students participated in this study. Sex predilection participated in the study is shown in eighty four percent of the study population [ $82 \%$ of female participants (272) and $89 \%$ of male participants (85)] did not have any TMJ symptoms. Fifty-nine females were affected among symptomatic patients who account for $18 \%$ of the female population, whereas only $10(11 \%)$ males were having symptoms. Among the study group, 69 students (16\%) were found to have signs and symptoms. 357 students were symptom free or without any symptoms that account for 84\%. [Table 1]

Out of the signs and symptoms present, sound in the TMJ was most common problem (45 students) which accounts for $10 \%$ followed by pain in 15 students (3\%) and fatigue in 7 students (2\%) in TMJ. On clinical examination, limited mouth opening was found in 40 students which accounts for $9 \%$ followed by locked mandible (10 students) $2 \%$, deviation (15 students) $3 \%$, and jaw rigidity of mandible (8 students) $2 \%$ during mouth opening [Table 2].

According to anamnestic component of Helkimo index, $84 \%$ students were free from symptoms, $13 \%$ students were found to have mild symptoms, and $1 \%$ students were having severe symptoms. According to clinical dysfunction component, $84 \%$ students were found to have no dysfunction, $15 \%$ students were having mild dysfunction, and only $2 \%$ students were having moderate dysfunction, whereas not a single student was having severe dysfunction. [Table 3].

\begin{tabular}{|c|c|c|c|c|c|}
\hline & No. of Patients & No. Signs of Pain & $\mathbf{\%}$ & Signs of Pain & $\mathbf{\%}$ \\
\hline Males & 95 & 85 & $89 \%$ & 10 & $11 \%$ \\
\hline Females & 331 & 272 & $82 \%$ & 59 & $18 \%$ \\
\hline Grand Total & $\mathbf{4 2 6}$ & $\mathbf{3 5 7}$ & $\mathbf{8 4 \%}$ & $\mathbf{6 9}$ & $\mathbf{1 6 \%}$ \\
\hline \multicolumn{6}{|c}{ Table 1. Sample Characteristic, Number and Sex Distribution }
\end{tabular}

Table 1. Sample Characteristic, Number and Sex Distribution

\begin{tabular}{|c|c|c|}
\hline Components & $\mathbf{N}=\mathbf{4 2 6}$ & Percentage \\
\hline Anamnestic Component & & \\
\hline Sound in TMJ & 45 & 10 \\
\hline Pain in TMJ & 15 & 3 \\
\hline Stress & 7 & 2 \\
\hline Clinical Dysfunction & 40 & 9 \\
\hline Limited mouth opening & 10 & 2 \\
\hline Locking of mandible & 15 & 3 \\
\hline Jaw deviation & 8 & 2 \\
\hline Reduced mandibular movement & 8 & \\
\hline Table 2. Prevalence of Signs and Symptoms among Students \\
\hline
\end{tabular}

\begin{tabular}{|c|c|c|c|}
\hline \multicolumn{2}{|c|}{ Sample Size (n) } & $\mathbf{4 2 6}$ & \\
\hline Components & Range & Counts & Percentage \\
\hline Anamnestic & & & \\
\hline A0 & & 357 & $84 \%$ \\
\hline AiI & & 54 & $13 \%$ \\
\hline AiII & & 4 & $1 \%$ \\
\hline Dysfunction & & & 857 \\
\hline Di0 & 0 & 62 & $15 \%$ \\
\hline DiI & $1-4$ & 7 & $2 \%$ \\
\hline DiII & $5-9$ & 0 & $0 \%$ \\
\hline DiIII & $9-25$ & \multicolumn{3}{l}{} \\
\hline Table 3. Evaluation of Helkimo Index Components among Students \\
\hline
\end{tabular}

\section{DISCUSSION}

This study was conducted to assess the prevalence of TMD among the dental students of Kharghar by the use of a selfreported questionnaire-based survey. The prevalence of TMD was found to be $16 \%$ in our study. Similar studies are present in the literature which have the same prevalence rates.[3,11] However, some studies in the literature found high prevalence rate in the same type of population.[12-14] The difference in prevalence rate in these reported studies may be due to size of sample, characteristic of the course of study and population.

In our study, there was discrepancy in the number of males and females participated in the study as the number of female students were higher in the college and more female students volunteered for the study. Females were preceded in the prevalence of TMJ disorder (18\%) than in males (11\%) which were in accordance with the study conducted by Johansson et al (2003)(16). A similar study conducted by Pedroni et al.(17) using anamnestic questionnaire found that around $68 \%$ participants were having TMD, of which $84 \%$ were females.

In the present study, TMJ sound (clicking or crepitus) $(10 \%)$ was the most common symptom which is slightly higher to the findings in the study done by Rani et al[3] and Gopal et al.[18] These were followed by pain (3\%) and fatigue in TMJ (2\%). The results are in accordance to the study done by Rani et al[3] and Hegde et al.[19] Clinical examination reveals limited mouth opening in most affected students 
(9\%) followed by locking of mandible (2\%), jaw deviation (3\%), and reduced mandibular movements (2\%) of TMJ.

In the present study, mild symptom Ail was found in $13 \%$ of cases which was higher to the findings present in the previous studies in the literature.[3-4] Mild symptoms (13\%) found in our study were more frequent than severe symptoms (1\%), this finding is consistent with other studies in the literature.[3,17-19] According to dysfunction component, $84 \%$ students were found to have no dysfunction, $15 \%$ students were having mild dysfunction, and only $2 \%$ students were having moderate dysfunction, whereas not a single student was having severe dysfunction. In our study, mild dysfunction symptoms were found in $15 \%$ of cases which was higher to the study done by Rani et al.[3]

The Helkimo index has been applied in a number of studies and it has been claimed that it is a good indicator of the severity of TMJ dysfunction. Undoubtedly, the merit of this index is that a fix set of symptoms was introduced with well-defined assignments of its parts and a computation of index class. This has resulted in a number of studies with comparable results concerning the presence of dysfunction and even better with presence of symptoms in patients subject to examination. Thus, using this information, well defined estimates have been revealed and comparison of the prevalence of symptoms in different population can be undertaken. ${ }^{[20]}$

In the present study, lower prevalence of TMDs was found as compared to other studies.[12] The limitations of this study that it consisted of a suitably selected sample size, and that the sample population of only dental students from one specific region. This study only provides information regarding the prevalence and TMD severity among dental students in Kharghar region of Navi Mumbai. Long-term studies should be carried out to investigate the relationship between TMD and its related problems focusing a larger population in different regions and different age groups.

\section{CONCLUSIONS}

Various epidemiological studies concerning the signs and symptoms of TMJ dysfunction have reported significant variation in prevalence rates, most likely due to methodological shortcomings than actual differences between sample characteristics. Regardless of this variation, it can be concluded that signs and symptoms of TMJ dysfunction are common. The Helkimo index can be used as an efficient tool in evaluating the prevalence of signs and symptoms of TMDs. Results from this study showed that the clinical signs and symptoms were present in non-patient population. It is important to understand that early TMD diagnosis can prevent future complications.

\section{REFERENCES}

[1] Schmitter M, Rammelsberg P, Hassel A. The prevalence of signs and symptoms of temporomandibular disorders in very old subjects. J Oral Rehabil 2005;32(7):467-73.
[2] Yekkalam N, Wänman A. Prevalence of signs and symptoms indicative of temporomandibular disorders and headaches in 35-, 50-, 65- and 75-year-olds living in Västerbotten, Sweden. Acta Odontol Scand 2014;72(6):458-65.

[3] Rani S, Pawah S, Gola S, et al. Analysis of Helkimo index for temporomandibular disorder diagnosis in the dental students of Faridabad city: a cross-sectional study. J Indian Prosthodont Soc 2017;17(1):48-52.

[4] Nassif NJ, Hilsen KL. Screening for temporomandibular disorders: history and clinical examination. American Dental Association. J Prosthodont 1992;1(1):42-6.

[5] Nilner M, Lassing SA. Prevalence of functional disturbances and diseases of the stomatognathic system in 7-14 year olds. Swed Dent J 1981;5(5-6):173-87.

[6] Osterberg T, Carlsson GE, Wedel A, et al. A crosssectional and longitudinal study of craniomandibular dysfunction in an elderly population. J Craniomandib Disord 1992;6(4):237-45.

[7] Goddard G, Karibe H. TMD prevalence in rural and urban Native American populations. J Craniomandib Pract 2002;20(2):125-8.

[8] Miller VJ, Karic VV, Myers SL, et al. The temporomandibular opening index (TOI) in patients with closed lock and a control group with no temporomandibular disorders (TDM): an initial study. J Oral Rehabil 2000;27(9):815-6.

[9] Lima DR, Brunetti RF, Oliveira W. Study of the prevalence of craniomandibular dysfunction using Helkimo's index and having as variables sex age and whether the subjects had or had not been treated orthodonticaly. Pós Grad Rev Fac Odontol São José Dos Campos 1999;2:127-33.

[10] Helkimo M. Epidemiological surveys of dysfunction of the masticatory system. Oral Science Review 1976;7:5469.

[11] Mutlu N, Herken H, Guray E, et al. Evaluation of the prevalence of Temporomandibular joint disorder syndrome in dental school students with psychometric analysis. Turk J Med Sci 2002;32:345-50.

[12] Bonjardim LR, Lopes-Filho RJ, Amado G, et al. Association between symptoms of temporomandibular disorders and gender, morphological occlusion and psychological factors in a group of university students. Indian Journal of Dental Research 2009;20(2):190-4.

[13] Modi P, Shaikh SS, Munde A. A cross sectional study of the prevalence of temporomandibular disorders in university students. Int J Sci Res Publ 2012;2(9):1-3.

[14] Nomura K, Vitti M, Oliveira AS, et al. Use of the Fonseca's Questionnaire to assess the prevalence and severity of temporo-mandibular disorders in Brazilian dental under-graduates. Brazilian Dental Journal 2007;18(2):163-7.

[15] De Oliveira AS, Dias EM, Contato RG, et al. Prevalence study of signs and symptoms of temporomandibular disorder in Brazilian college students. Brazilian Oral Research 2006;20(1):3-7.

[16] Joshansson A, Unell L, Carlsson GE, et al. Gender differences in symptoms related to temporomandibular disorders in a population of 50 years old subjects. J of Orofacial Pain 2003;17(1):29-35. 
[17] Pedroni CR, De Oliveira AS, Guaratini MI. Prevalence study of signs and symptoms of temporomandibular disorders in university students. J Oral Rehabil 2003;30(3):283-9.

[18] Gopal KS, Shankar R, Vardhan HB. Prevalence of temporo-mandibular joint disorders in symptomatic and asymptomatic patients: a cross-'sectional study. Int J Adv Sci 2014;1:14-20.
[19] Hegde V. A review of the disorders of temperomandibular joint. J Indian Prosthodont Soc 2005;5(2):56-61.

[20] Otuyemi OD, Owotade FJ, Ugboko VI, et al. Prevalence of signs and symptoms of temporomandibular disorders in young Nigerian adults. Journal of Orthodontics 2000;27(1):61-5. 